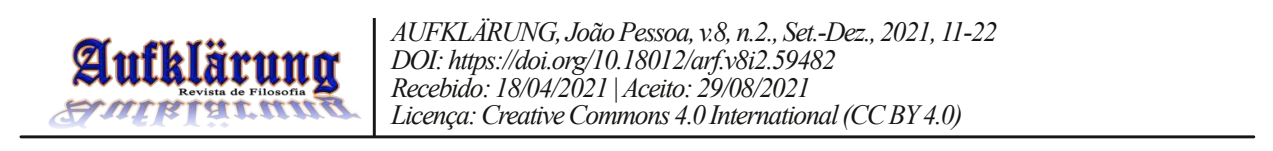

\title{
CONFLICTO Y SUPERIORIDAD: LA VIDA Y SU MÁS ALLÁ EN NIETZSCHE Y FREUD
}

\author{
[Conflict And Superiority: LifE and its Beyond in Nietzsche and Freud]
}

\author{
Alonso Zengotita* \\ Universidad de Buenos Aires, Argentina
}

\begin{abstract}
RESUMEN: Al abordar las relaciones NietzscheFreud respecto al concepto de vida, la noción de límite interno-externo del viviente -es decir, el límite del propio viviente con el exterior- ha sido desarrollada de modo escaso o tangencial. En el presente artículo se buscará utilizar dicha noción -en términos de herramienta analíticapara dar cuenta no sólo de la relación que el viviente presenta desde su conflictividad inherente respecto a las fuerzas que le son externas, sino también para dar cuenta, al abordar lo propio del hombre, del límite de la vida misma - es decir, dar cuenta del punto a partir del cual aparece aquello más allá de la vida propiamente humana.
\end{abstract}

Palabras Clave: Nietzsche, Freud, vida, limite, conflicto
ABstract: When approaching the NietzscheFreud relations with respect to the concept of life, the notion of the internal-external limit of the living being - that is, the limit of the living being itself with the outside - has been developed in a scant or tangential way. In this article we will seek to use this notion -in terms of an analytical tool- to account not only for the relationship that the living being presents from its inherent conflict with respect to the forces that are external to it, but also to account for the to address what is proper to man, the limit of life itself - that is, to account for the point from which that beyond the properly human life.

KEYwords: Nietzsche, Freud, life, limit, conflict

\section{INTRODUCCIÓN}

A 1 abordar las relaciones Nietzsche-Freud, el concepto de vida presenta diversos análisis. Por mencionar algunos, el trabajo de J. Faulkner (2003) destaca el carácter expansivo en la noción vital nietzscheana y el conservador en la noción freudiana -perspectiva que puede asimismo hallarse en el libro de Uribe (2002), así como en el de Reginster (2006). Steineger (2004) caracteriza las perspectivas tanto de Nietzsche como de Freud como relativistas, y por tanto concluye un incurrir en contradicción por parte de los mismos al especificar propuestas vitales específicas, articuladas a secuencias históricas. Vázquez Rocca (2014) trabaja sobre las nociones de instinto y pulsión en función del modo en que la moralidad, la mala conciencia y la construcción superyoica inciden sobre la dinámica vital. El artículo de Fernández García (2005) analiza el malestar como parte de un juego trágico-vital, que es expuesto por Nietzsche en forma de metafísica, y analizado por Freud al modo terapéutico psicoanalitico, sostenido desde una techné cientificista.

* Doctor en Filosofía por la Universidad de Buenos Aires, UBA. Buenos Aires, Argentina. E-mail: alonsozengotita@gmail.com 
Existen asimismo análisis que trabajan más globalmente dicha relación, como el clásico de Assoun (2008), quien atendiendo a la problemática relativa al campo epistemológico de enunciación (filosofía y psicología), trabaja comparativamente conceptos base en torno a la vida (pulsión e instinto, sublimación y arte, Eros y Dionisos, libido y poder). Gasser (1997) ahonda en la crítica a la metafísica como discurso, tanto desde el punto de vista nietzscheano como desde el psicoanálisis como instrumento de Metaphysikkritik, articulándolo a la conflictividad vital, y ahonda sobre el concepto de vida desde el punto de vista del deseo por el poder -y por la muerte, en el sentido de la compulsión de repetición (Wiederholungszuang). Almeida (2005), en su articulación entre las nociones de eterno retorno y compulsión de repetición, ensaya un recorrido de similitudes en torno a la dinámica vital en la obra de ambos autores -abordaje compartido asimismo por Chapelle (1993) en su libro.

En los recorridos mencionados, la noción de límite interno-externo del viviente -es decir, el límite del propio viviente con el exterior- ha sido desarrollada de modo escaso o tangencial. En el presente artículo se buscará utilizar dicha noción -en términos de herramienta analitica- para dar cuenta no sólo de la relación que el viviente presenta desde su conflictividad inherente respecto a las fuerzas que le son externas, sino también para dar cuenta, al abordar lo propio del hombre, del limite de la vida misma -es decir, dar cuenta del punto a partir del cual aparece aquello más allá de la vida propiamente humana.

En orden de lograr el objetivo explicitado, se desplegará en un primer momento el modo en que la vida es concebida por Nietzsche en términos de Wille zur Macht, y por Freud desde su último modelo pulsional, articulada a la manera en que ambos conciben al 'hombre superior' -justamente en tanto el mismo supondrá un limite. A partir de dicha articulación se buscará, partiendo del carácter conflictivo inherente que lo vital presenta para ambos, disponer cómo desde el límite que implica la figura tipológica del 'hombre superior' es posible determinar asimismo el limite de lo vital humano -y por ende, la apertura a un espacio más allá de la vida humana.

\section{NiETZSCHE: LA SALUD, EL RIESGO, EL DIEZMADO}

Nietzsche plantea en La genealogía de la moral, refiriéndose a la perspectiva sobre lo vital imperante en su tiempo:

(...) bajo la presión de aquella idiosincracia se coloca en el primer plano a la 'adaptación' (Anpassung), es decir, una actividad de segundo rango, una mera reactividad (Reaktivität), más aún se ha definido la vida misma como una adaptación interna, cada vez más apropiada, a las circunstancia externas (Herbert Spencer). (...) con ello se pasa por alto la supremacía de principio que poseen las fuerzas espontáneas, agresivas, invasoras, creadoras de nuevas interpretaciones, de nuevas direcciones y formas, por influjo de las cuales viene luego la 'adaptación'; con ello se niega en el organismo mismo el papel dominador de los supremos funcionarios, en los que la voluntad de vida aparece activa y conformadora.' ([1887] 2000, p. 47)

Nietzsche no niega las capacidades vitales ligadas a la conservación sino que denuncia, en el discurso biológico imperante -el darwiniano/spenceriano- la obliteración de las otras, las activas. Ahora bien, esta capacidad activa es tal en tanto las fuerzas correspondientes tienden a la invasión y al dominio:

[1]a vida no es adaptación de condiciones internas a condiciones externas sino voluntad de poder que, desde el interior, somete e incorpora a sí cada vez más 'exterior' (...) La apropiación e incorporación es sobre todo un querer subyugar, un formar, configurar y reconfigurar hasta que finalmente lo sometido ha pasado totalmente al poder del atacante y lo ha acrecentado. -Si esta incorporación no 
tiene éxito, la formación probablemente se desintegra (...) (Nietzsche, [1888] 2008, 9[151], p. 282)

El acrecentamiento vital implica entonces una capacidad activa de ataque respecto de un 'exterior' - que cuenta asimismo con fuerzas- y cuya lucha puede presentar o no éxito. Ahora bien, el grado de probabilidad de dicho éxito se articula a otra lucha, interna al viviente:

[1]a contraposición de las pasiones, la duplicidad, la triplicidad, la multiplicidad de las 'almas en un único pecho'2: muy insano, ruina interna, disgregante, delatando e intensificando una disensión y un anarquismo internos: a no ser que una pasión finalmente acabe por dominar. Retorno de la salud - (Nietzsche, [1888] 2008, 14[157], p. 584)

Un interior dividido por lucha interna de pasiones - de fuerzas- decanta en la debilidad del viviente. La llegada de la salud se da a través del dominio de una de ellas; ¿esto implica entonces la unicidad total del viviente?

La pasión dominante, la cual lleva consigo incluso la forma suprema de la salud en general: aquí se alcanza de manera óptima la coordinación de los sistemas internos y el concurso de sus trabajos al servicio de una unidad -pero, ¡esto es prácticamente la definición de la salud! ([1888] 2008, 14[158], p. 584)

No hay una disolución de la multiplicidad de fuerzas, sino una coordinación de las mismas en pos de una determinada perspectiva -aquella de la fuerza que ha logrado imponerse. Al haberse operado un dominio ordenador hacia el interior, el viviente procede a proyectar sus fuerzas hacia un afuera, generando una exteriorización del conflicto -y entonces dando lugar, desde esta configuración de la 'gran salud' (Große Gesundheit $)^{3}$, a la maximización de posibilidades para tener éxito en la incorporación de exterior.

Desde la perspectiva de la vida como Wille zur Macht, el estadio óptimo de salud es aquel que reconfigura la totalidad de las fuerzas internas -tanto las activas como las propias de la Reaktivität- en función de la imposición de una perspectiva determinada, tendiente al plus de poder. Así caracteriza entonces Nietzsche al tipo de la 'gran salud': '[e]sta 'audacia' de las razas nobles (...) y su desprecio por la seguridad (...)' ([1887] 2000 , p. 55). La tendencia al plus de poder, a la incorporación de exterior a través de la lucha supone un desprecio por la propia seguridad -justamente en tanto la conservación es una 'actividad de segundo rango, una mera reactividad'.

Ahora bien, este arriesgarse y luchar continuo presenta a su vez consecuencias:

\section{[p]roblema----}

Las razas fuertes se diezman recíprocamente: guerra, ansias de poder, aventura; su existencia es costosa, breve, -se extenúan entre ellas- (...) Los fuertes son posteriormente más débiles, más desprovistos de voluntad, más absurdos que los medianamente débiles

Son razas derrochadoras.- (...)

Nos encontramos ante un problema de economía--- ([1888] 2008, 14 [182], p. 601)

El extremar la capacidad activa, poniéndola como tendencia absoluta, genera finalmente el efecto contrario: extenuación, diezmado, debilidad. No hay así una suerte de fórmula estable, constante, para la ascendencia vital: la misma se resuelve a través de la lucha, el azar y el cambio continuos. 


\section{FREUD: LA OPOSICIÓN, LA UTOPÍA, LA DEFENSA}

A través de la obra de Freud, la noción de vida resulta parte integral -en distintas formas- de sus diversos modelos para abordar lo psíquico. Desde su Proyecto para una psicología -que intenta la síntesis sistemática de los primeros elementos teóricos freudianos $^{4}$ y los nuevos hallazgos de la neurologia ${ }^{5}$-, donde 'exigencias de la vida' generan transformaciones respecto al aparato psíquico, llegando hasta el modelo pulsional desplegado en Más allá del principio del placer donde la especulación se produce respecto a la noción misma de vida, los modelos psíquicos presentan siempre articulaciones al modo en que lo vital es concebido.

Freud utiliza para dar cuenta de sus modelos psíquicos a la noción de pulsión, que es concebida como 'agencia representante (Repräsentanz) psiquica de una fuente de estímulos intrasomática en constante fluir' ([1915] 1992, tomo VII, p. 153); esta representación de estimulos es caracterizada en términos de oposición conflictiva. Esta caracterización es introducida, respecto a su primer modelo pulsional -pulsiones yoicas y pulsiones sexuales- en un texto de 1910, La perturbación psicógena de la visión según el psicoanálisis. Dichas perturbaciones psicógenas se basan en la separación -vía represión- de ciertas representaciones visuales respecto del campo de la conciencia. Ante esto Freud estipula que '(..) el abordaje psicoanalítico supondrá que esas representaciones han entrado en una oposición con otras, más intensas - para las cuales empleamos el concepto colectivo de 'yo' (...)' ([1910] 1992, tomo XI, p. 211). Sin embargo, añade que

'(...) las oposiciones entre representaciones no son sino la expresión de las luchas entre las pulsiones singulares. De particularísimo valor para nuestro ensayo explicativo es la inequívoca oposición entre las pulsiones que sirven a la sexualidad, la ganancia de placer sexual y aquellas otras que tienen por meta la autoconservación del individuo, las pulsiones yoicas.([1910] 1992, tomo XI, p. 211)

Esta caracterización de oposición conflictiva se sostiene, y resulta fundamental para dar cuenta del último ${ }^{6}$ gran modelo pulsional, que atañe de modo directo a la concepción vital freudiana: pulsiones de muerte y pulsiones de vida. A partir de esta última concepción es que Freud aborda la problemática de la guerra, desde la cual despliega la noción del 'hombre superior'.

En su escrito de 1933 ¿Por qué la guerra?, Freud -respondiendo a una carta de Einstein ${ }^{7}$ - aborda la cuestión de la posibilidad de prevenir -e incluso hacer cesar- la guerra. A partir de su último modelo pulsional busca dar cuenta de la facilidad con que aquella se produce: no sólo hay pulsiones de vida o eróticas, sino también mortiferas. Estas últimas, entrelazándose con las primeras, facilitan el entusiasmo bélico (el gusto destructivo mismo articulado a ideales diversos).

Pero si es natural tender a lo destructivo, ¿de dónde viene la indignación y repulsa a la guerra? Porque todo ser humano tiene derecho a no tener que dañar al prójimo, a proteger su propia vida, etc. etc. Estos son, establece Freud, formas de justificación asociadas al desarrollo evolutivo cultural -pero sustentadas orgánicamente: '[s]ensaciones que eran placenteras para nuestros antepasados son indiferentes o aún desagradables para nosotros; el hecho de que nuestras exigencias ideales éticas y estéticas se hayan modificado tiene un fundamento orgánico.' ([1933] 1992, tomo XXII, p. 198). El avance civilizatorio implica por un lado el progresivo dominio de las tendencias pulsionales por lo intelectual, y por otro - directa consecuencia del anteriorla introyección de la agresividad (con sus aspectos positivos y negativos). El desenvolvimiento bélico aparece asi como la destrucción de lo civilizatorio -y por ende Freud dirá: 'todo lo que impulsa el desarrollo de la cultura trabaja también contra la guerra'. La autodestrucción propia de la guerra -en efecto: el ser humano es tanto quien destruye como lo destruido- pone enfrente a la civilización como un dique de 
conservación de lo vital; tanto el dominio intelectual como la introyección de las pulsiones agresivas implican la coartación de la agresividad para con el otro.

Y sin embargo, frente a toda esta actividad civilizatoria los eventos bélicos no han desaparecido. Freud entonces dispone:

[1]o ideal sería, desde luego, una comunidad de hombres que hubiese sometido su vida pulsional a la dictadura de la razón. Ninguna otra cosa podría llevar a una unidad tan completa y resistente entre los hombres, aunque se renunciara a los lazos afectivos entre ellos. Pero con toda probabilidad esta es una esperanza utópica.' (ibid, p. 196)

Ante una comunidad en la cual no hay proyección agresiva pulsional (pero tampoco afectiva), la guerra cesaría de existir. Una comunidad puramente pragmática, a la manera de un gran ser vivo que ha deshecho la autodestrucción -y que entonces no tiene sino que defenderse de los posibles peligros exteriores.

Pero la perfección en el coartar las pulsiones es utópica, sostiene Freud; así, plantea la posibilidad de formar un 'estamento superior de hombres de pensamiento autónomo, que no puedan ser amedrentados y luchen por la verdad, sobre los cuales recaería la conducción de las masas heterónomas.' (ibídem). Aparece una doble divergencia respecto al planteo utópico: no se trata de una razón dictatorial, en donde no hay proyección pulsional, sino de una capacidad autónoma de pensamiento -es decir, la capacidad de poder soportar, de no amedrentarse bajo los impactos de fuerzas tanto del interior como del exterior ${ }^{8}$. Por otro lado, ya no es la totalidad de la comunidad sino una parte quien ha de presentar esas caracteristicas -los que serán el 'estamento superior'. Una parte diferenciada, entonces, de ese gran organismo que es la comunidad, y que actúe como su razón, dirigiendo sus tendencias pulsionales de modo de evitar la autodestrucción.

Esta tendencia conservativa de lo vital que Freud resalta se articula a una concepción más general de la vida misma. En efecto, así caracteriza a la vida en su origen:

[e]sta partícula de sustancia viva flota en medio de un mundo exterior cargado (laden) con las energías más potentes, y sería aniquilada por la acción de los estímulos que parten de él si no estuviese provisto de una protección antiestímulo (Reizschutz). (...) Para el organismo vivo, la tarea de protegerse contra los estímulos es casi más importante que la de recibirlos (...)' ([1920] 1992, tomo XVIII, p. 24)

La relación entre el viviente y las fuerzas externas aparece invertida respecto a la caracterización nietzscheana: no se trata de que el viviente ha de irrumpir en el exterior, buscando asimilarlo, sino que primariamente ha de buscar defenderse del carácter hipertrófico propio de las fuerzas de ese afuera. No es entonces la expansión sino la conservación respecto al exterior la tónica vital primaria.

\section{FORTIFICACIÓN E INDIFERENCIACIÓN DEL LÍMITE: EL VÍNCULO DE LO INTERNO Y LO EXTERNO}

Al abordar la noción de sentir religioso, Freud analiza en El malestar en la cultura la manera en que -en correspondencia con él- Romain Rolland se lo describe: es 'oceánico', el 'sentimiento de indisoluble unión, de inseparable pertenencia con el mundo exterior' ([1930] 1992, tomo XXI, p. 65); según Freud, '[y]o no puedo descubrir en mí mismo ese sentimiento "oceánico" (ibid, p. 66) -pero sin embargo busca dar cuenta del mismo. Ese sentir resultaria una instancia regresiva, infantilismo propio de la época en la cual el individuo no se considera aun a si mismo como distinto del mundo exterior. Lo que se halla problematizado -lo que resulta psíquicamente débil- es el límite -en tanto que separa y a la vez une- entre lo interno y lo externo al individuo. 
Como Freud establece en 1923 en El yo y el ello, el yo es considerado 'una pobre cosa sometida a tres servidumbres y que, en consecuencia, sufre las amenazas de tres clases de peligros: de parte del mundo exterior, de la libido del ello y de la severidad del superyó.' ([1923] 1992, tomo XIX, p. 56). La labor psicoanalitica busca 'merced al fortalecimiento del yo, sustituir la decisión deficiente que viene de la edad temprana por una tramitación correcta.' ([1937] 1992, tomo XXIII, p. 231). En tanto el yo actúa como mediación entre el ello y el mundo exterior (Außenwelt $)^{9}$, entonces es el fortalecimiento del límite lo que es propiamente saludable.

Freud no encuentra en sí ese sentir 'oceánico' nombrado por Rolland ya que en él se daría el caso de quien ha logrado reelaborar esos lazos infantiles fallidos, generando una estructura consistente y saludable en términos de limitación interior/exterior.

Frente a esta caracterización de debilidad psíquica propia del niño, Nietzsche planteará algo rotundamente divergente. En Así habló Zarathustra -'De las tres transformaciones'- se despliega cómo se transforma el espíritu -camello, león y finalmente niño.

Mas ahora decidme, hermanos míos: ¿qué es capaz de hacer el niño, que ni siquiera el león haya podido hacer? ¿Para qué, pues, habría de convertirse en niño el león carnicero?

Sí, hermanos míos, para el juego del crear se necesita un santo decir 'si': el espíritu lucha ahora por $s u$ voluntad propia, el que se retiró del mundo conquista ahora $s u$ mundo. ([1885] 2007, p. 43)

El carácter realzado del niño, en tanto figura última del espíritu, es aquel del 'juego del crear', justamente pues implica la capacidad de generar nuevas configuraciones vitales -es decir, justamente en tanto juega con los límites, modificándolos ${ }^{10}$. Así como en Freud, el niño es aquel que no presenta una delimitación clara respecto a ese mundo exterior -sólo que, para Nietzsche, esa maleabilidad del limite representa una capacidad de empoderamiento -y por ello 'el espíritu lucha ahora por $s u$ voluntad propia'-, una tendencia al aumento de poder. Esa labilidad del límite es lo que supone justamente la posibilidad del viviente de franquearlo y darle nueva forma: 'La apropiación e incorporación es sobre todo un querer subyugar, un formar, configurar y reconfigurar hasta que finalmente lo sometido ha pasado totalmente al poder del atacante y lo ha acrecentado.' ([1888] 2008, 9 [151], p. 282).

La trayectoria tipológica para la vida saludable parece así apuntar en sentidos opuestos respecto del limite. Por un lado, la labor psicoanalítica busca levantar resistencias (Widerstände) hacia dentro del aparato psíquico, -resistencias generadas mientras dicho aparato no se hallaba aun completamente desarrollado. En esta línea, el hombre perteneciente al 'estamento superior' es aquel que ha hecho caer completamente sus resistencias, al lograr dominar vía sumisión a pautas racionales el frente de peligro interno que resultan las pulsiones. Inaccesible a la intimidación, es decir, perfectamente protegido del exterior, el hombre superior es a su vez aquel que no se halla partido internamente -que ha terminado con sus represiones, y logra una correcta fluidificación energética. En tanto 'el yo combate en dos frentes: tiene que defender su existencia contra un mundo que amenaza aniquilarlo, así como contra un mundo interior demasiado exigente' ([1937] 1992, tomo XXIII, p. 201), el sostenimiento del límite entre lo interno y lo externo implica el adecuado manejo de ambos frentes.

Por otro lado, la disposición vital nietzscheana de la 'gran salud' (Große Gesundheit) como jerarquización conformada a partir de un impulso rector tiende primariamente a cruzar dicho limite interno-externo -en tanto 'la voluntad de poder sólo puede exteriorizarse ante resistencias.' Si la 'gran salud' del hombre superior supone en Freud, el inquebrantable sostenimiento de un límite interno-externo que no sucumba bajo amenazas -ya internas, ya externas-, la Große Gesundheit del hombre superior nietzscheano solamente pone un límite -es decir, produce una cierta configuración- para después romperlo ${ }^{11}$. Así, inversamente, a lo que se tiende no es a la perfecta delimitación 
interno-externo sino a su indiferenciación -a su constante puesta en riesgo:

el sentir 'oceánico' de Romain Rolland, puesto al servicio del aumento del poder- resulta el punto culminante.

\section{El CONFLICTO Y SU MÁS ALLÁ: EL LÍMITE A LA VIDA}

Ahora bien, esta lectura parcializa las perspectivas de Freud y Nietzsche en tanto oblitera un aspecto esencial de la concepción de vida: el conflicto, la lucha. En efecto, Nietzsche afirma que 'mediante un ser orgánico, no un ser sino la lucha misma quiere conservarse, crecer y ser consciente de sí.' ([1888] 2008, 1[124], p. 62). Freud indica: 'la lucha entre Eros y Muerte (...). Esta lucha es el contenido esencial de la vida en general (...)’ ([1933] 1992, tomo XXI, p. 118). La noción de que lo fundamental de la vida es el conflicto propio de las fuerzas que la componen deshace la unidireccionalidad vital presentada a partir de las tipologias superiores. Freud afirma, respecto a sus tiempos:

[h]emos manifestado la inequívoca tendencia a hacer a un lado la muerte, a eliminarla de la vida. Hemos intentado matarla con el silencio (...) Ahora bien, esta actitud frente a la muerte tiene un fuerte efecto sobre nuestra vida. La vida se empobrece, pierde interés, cuando la máxima apuesta en el juego de la vida, que es la vida misma, no puede arriesgarse. Se vuelve tan insípida e insustancial como un flirt norteamericano, en que de antemano se ha establecido que nada puede suceder (...)' ([1915] 1992, tomo XIV, p. 290-1)

Esta caracterización permite volver sobre el concepto de la utopía propia de la dictadura de la razón: una vida en donde nada pasa, en donde la ordenación relacional está dada de modo puramente pragmático, en donde no hay amor ni odio -la vida insustancial. En términos éticos y estéticos, la sustancialidad de la vida solamente aparece al momento en que la vida puede arriesgarse -en el momento en que hay conflicto.

En Nietzsche, las razas nobles desprecian su seguridad, tienden a la continua ruptura del límite interno-externo buscando acrecentar su poder. Sin embargo, como se había marcado, si dicha tendencia resulta extrema finaliza en el diezmado y la debilidad general de dicha comunidad. Este ‘problema económico' es contemplado por Nietzsche. En efecto, así caracteriza a las culturas que él ha considerado ascendentes -la griega, la romana, la renacentista:

[h]ay allí un subyugar la plenitud de lo viviente, la medida se vuelve dominante, a la base está esa calma del alma fuerte que se mueve con lentitud y tiene aversión a lo demasiado vivaz. Se honra y se eleva el caso general, la ley; la excepción, por el contrario, es dejada de lado; el matiz, borrado. Lo firme, poderoso, sólido, la vida que reposa extendida y potente -eso 'gusta' (...).' ([1888] 2008, 7[7], p. 209)

¿No contradice esto la perspectiva anterior? ¿Cómo es posible hablar por un lado del desprecio por la seguridad, y por otro de la aceptación y honra de lo establecido como general y lo firme? El problema pasa allí por una confusión conceptual producto de una lectura sesgada de dicha perspectiva anterior -a saber, el hacer corresponder a la maximización del riesgo con la tendencia al plus de poder. Articulando los tres elementos puestos en juego - la raza noble, el diezmado y el caso general- es posible dar cuenta de por qué Nietzsche da esta última caracterización. Si, como un todo, la comunidad tiende a la pura puesta en riesgo -a la indiferenciación del límite interno/ externo- se llega al diezmado. Así, una cultura que tiende a la elevación dispone de leyes que, justamente, no son puestas en riesgo sino honradas. Hay allí una correspondencia estructural para con la noción de 'gran salud': la totalidad de las partes puestas en coordinación desde una perspectiva determinada. Esa perspectiva, cual ley general, es lo 
honrado en función de potenciar a la comunidad en términos de plus de poder. De este modo, en la cultura ascendente hay norma y hay regla general -no hay pura ruptura ${ }^{12}$. Dicho de otro modo: no hay pura indiferenciación del límite interno/externo, sino que el mismo se deshace para volverse a construir en función de dicha ley general -si es que la asimilación ha sido exitosa. Si de hecho a lo que se tendiese fuese la maximización del 18 riesgo -correspondiente a una indiferenciación del límite interno/externo- lo más favorable no resultaria buscar la coordinación de las fuerzas internas sino deshacerla -por supuesto: cuanto más anárquico sea el viviente hacia su interior, más riesgoso es su intento de lucha y asimilación del exterior. La vida lo que busca no es maximizar el riesgo sino el poder: justamente por eso la gran salud implica la menor anarquía posible hacia el interior del viviente para maximizar sus posibilidades de éxito en la lucha externa. Desde aquí es posible reinterpretar la noción de las razas nobles y su desprecio por la seguridad: la maximización del riesgo, al no ser algo buscado de por sí, se halla al servicio del aumento de poder -y por ende, el desprecio por la seguridad refiere a la tendencia a maximizar el riesgo externo a partir de un minimo de riesgo interno (lo que implica un máximo interno de coordinación, $v$. $g r$, la honra de la ley general), lo cual supone la mejor fórmula en pos del poder.

Ya sea en términos de la Kultur nietzscheana o de la Zivilisation freudiana ${ }^{13}$, lo que se halla es una modelización en términos del viviente: la Kultur nietzscheana adquiere la coordinación en términos de ley de la Große Gesundheit, mientras que en Freud la civilización funge como limite frente a las fuerzas autodestructivas de la humanidad -y habiendo fallado ese dique, el 'estamento superior' se dispone como yo, como aquello que ha de limitar y manejar la locura tanática propia de ese gran organismo que conforma la humanidad ${ }^{14}$. En ambos casos, asimismo, se trata de manejar la conflictividad extrema a través de una instancia ordenadora: la ley general en Nietzsche, que impide la pura maximización del riesgo, y la limitación por la civilización o por el 'estamento superior' de la exacerbación tanática en Freud.

Tanto en Nietzsche como en Freud, lo vital se despliega desde el conflicto de fuerzas -activas y reactivas en el primero, de vida y muerte en el segundo ${ }^{15}$. Al abordar las respectivas tipologías superiores - las 'razas fuertes' que desprecian su seguridad y la comunidad bajo la 'dictadura de la razón'- pareció conformarse un panorama diverso: el rasgo común conflictivo se difuminó y, en términos de la herramienta analítica del límite interno-externo del viviente, lo superior apuntó hacia aspectos opuestos -una perfecta delimitación en Freud, una indiferenciación del límite en Nietzsche. Ahora bien, ambos elementos -la oposición, y la difuminación del conflicto- son estructuralmente correspondientes: es en la pérdida de la conflictividad -el coartamiento pulsional por un lado, la indiferenciación interno-externo por otro ${ }^{16}$ - que se dibuja la oposición tipológica. Justamente en tanto el conflicto ha de ser parte de lo vital es que Freud califica a la comunidad de la dictadura de la razón como utópica -y pone en juego el 'estamento superior'- y Nietzsche pone a las culturas superiores como aquellas que honran la ley general: tanto en un caso como en otro, se trata de una coordinación determinada del conflicto, y no de su abolición ${ }^{17}$.

Ahora bien, ¿qué representan entonces la 'dictadura de la razón' y el puro 'desprecio por la seguridad'?

La utopía freudiana implicaba un sometimiento completo de lo pulsional a la razón: la perfectibilidad máxima del límite interno-externo elimina los lazos afectivos y la agresividad. Ahora bien, si como Freud indica lo esencial de la vida es la lucha entre Eros y Muerte, entonces la utopía freudiana apunta a una vida sin esencia -a otra cosa que la vida, una humanidad más allá de lo humano: una comunidad unificada de modo puramente pragmático, que al eliminar todo conflicto conforma una suerte de gran organismo humano.

Del lado nietzscheano, la maximización del riesgo implicaba una indiferenciación del límite interno-externo: allí, entonces, ya no hay una vida distinguible de lo exterior -desapareciendo entonces el conflicto ${ }^{18}$ - ya no hay algo propio de lo que es la vida misma. En el extremo de las 'razas fuertes', la indiferencia en el 
límite interno-externo supone así un más allá de la vida del hombre: en esa instancia en donde ya no existen siquiera las leyes generales propias de la comunidad de la 'gran salud', donde la figura del niño representa el puro juego de construcción y destrucción de relaciones, se abre el camino de la superación del hombre por el Übermensch ${ }^{19}$.

En términos de un metanivel analítico respecto a esta indagación de lo vital en Freud y Nietzsche a partir de la noción de límite, es posible determinar entonces que las figuras -justamente- límite de la superioridad -la utópica y la de la indiferenciación del limite- fungen como límite mismo a la concepción de vida humana - es decir, marcan el punto a partir del cual lo que se despliega es otra cosa que la vida propiamente humana.

Ya sea en la figura de la comunidad perfectamente unificada o en aquella del Übermensch, el más allá de la vida humana se grafica por el cese del conflicto entre fuerzas propias $-\mathrm{y}$ por ende, la inutilidad de las reglas ${ }^{20}$. Esto implica la desaparición de la ética y de la estética humanas -en Freud, porque ya no hay lazos agresivos ni afectivos; en Nietzsche, porque lo que aparece es justamente el más allá de la ética y la estética entendidas humanamente.

Pero más acá, del lado humano, el conflicto es lo que principalmente genera el despliegue vital. Y justamente porque la vida es conflictiva es que su despliegue implica aspectos éticos y estéticos: se lucha por y desde una perspectiva -entre otras.

La noción de limite, asi, no implica un aspecto secundario o lateral al momento de abordar la noción de vida en el pensamiento de Nietzsche y Freud, sino que demarca el modo en que el conflicto inherente a lo vital se despliega, para cada uno, en términos de tendencias $-\mathrm{y}$ que por ende implica aspectos éticos y estéticos, ya sea frente a la guerra o frente a la búsqueda de un plus de poder, u otro escenario. Pero asimismo marca un límite al conflicto -un límite a lo propio de la vida humana misma- abriendo el espacio hacia un más allá, hacia la posibilidad de concebir otra cosa que la vida humana. De este modo, la relación estructural del límite interno-externo delinea un fundamento específico del proyecto vital hacia dentro de las obras de ambos pensadores.

\section{REFERÉNCIAS}

ALMEIDA, R. Nietzsche e Freud, eterno retorno e compulsão à repetição. São Paulo: Loyola, 2005.

ASSOUN, P.-L. Freud et Nietzsche. Paris: P.U.F, 2008.

BARCALETT PÉREZ, M. L. Friederich Nietzsche: la vida, el cuerpo la enfermedad. Méjico DF: Univ. Autónoma de Méjico, 2006.

BERCHERIE, P. Génesis de los conceptos freudianos. Buenos Aires: Paidós, 1996.

BOOTBHY, R. Freud as philosopher, -Metapsychology aflter Lacan. Londres: Routledge, 2001.

CHAPELLE, D. Nietzsche and psychoanalysis. Albany: State Univ. of New York Press, 1993.

FAULKNER, J. 'The Body As Text In The Writings of Nietzsche And Freud', Minerva, 6, pp. 94124, 2003.

FERNÁNDEZ GARCÍA, E. 'En torno al malestar: aproximaciones de Nietzsche y Freud'. MalEstar Subjetivo, 1 (1), pp. 10-42, 2005.

FREUD, S. Obras completas. Buenos Aires: Amorrortu, 1992.

GASSER, R. Nietzsche und Freud. Berlín: De Gruyter, 1997.

GEMES, K. 'Postmodernism's Use and Abuse of Nietzsche', Philosopy and Phenomenological Research, vol. LXII, N. 2, pp. 337-369, 2001.

GREEN, A. Pourquoi les pulsions de destruction ou de mort? Paris: Ithaque, 2010.

KAUFMANN, P. Elementos para una enciclopedia del psicoanálisis. El aporte freudiano. Barcelona: Paidós, 1996.

LAPLANCHE, J. Vida y muerte en psicoanálisis. Buenos Aires: Amorrortu, 1970.

NIETZSCHE, F. Fragmentos póstumos, vol. IV. Madrid: Tecnos, 2008.

NIETZSCHE, F. Genealogía de la moral. Madrid: Alianza, 2000. 
NIETZSCHE, F. Asi habló Zarathustra, Madrid: Alianza, 2007.

NIETZSCHE, F. Ecce Homo, cómo se llega a ser lo que se es. Madrid: Alianza, 1979.

NIETZSCHE, F. La ciencia jovial. Madrid: Biblioteca Nueva, 2001.

OLAFFSON, F. 'Nietzsche's Philosophy of Culture: A Paradox in The Will to Power', Philosophy and Phenomenological Research, vol. 51, n. 3, pp. 557-572, 1991.

20 REGINSTER, B. The affirmation of life: Nietzsche on overcoming nihilism. Harvard: Harvard Univ. Press, 2006.

STEINEGER, J. 'Friederich Nietzsche and Sigmund Freud failure: a tomist protest on truth', Quodlibet Diary, 6 (1), pp. 23-38, 2004.

STIEGLER, B. '¿Qué cambia poner el cuerpo en el lugar del alma? Nietzsche entre Descartes, Kant y la biología', Eidos, vol. 1, pp. 128-141, 2003.

SULLOWAY, F. J. Freud, biologist of the mind. Harvard: Harvard University Press, 1992.

URIBE, D. Vitalismo cósmico. Bogotá: Siglo del Hombre, 2002.

VATTIMO, G. Diálogo con Nietzsche. Buenos Aires: Paidós, 2002.

VÁZQUEZ ROCCA, A. 'Nietzsche y Freud, negociación, culpa y crueldad: las pulsiones y sus destinos, "eros" y "thanatos" (agresividad y destructividad)', Eikasia, 57, pp. 67-97, 2014.

\section{NoTAS}

1 Estas comillas son reflejo de las utilizadas por Nietzsche en la anterior cita; las mismas refieren al carácter eventual de dicho exterior: en tanto el propio viviente es conformación de fuerzas en conflicto, lo que el 'interior' y 'exterior' le resultan es -justamente a partir de su carácter transformativo- eminentemente no determinado. Entendiéndose así, no se usarán las comillas al referir en lo subsiguiente dicho concepto -como también su complementario, 'interior'. Esto, por supuesto, se continuará al abordar la concepción de 'límite'.

2 Alusión al libro I del Fausto de Goethe.

3 Este carácter propio de la gran salud es la que Barbara Stiegler otorga como tendencia, en una inversión del modelo cartesiano-moderno, a la generalidad cuerpo nietzscheano: 'Mientras que Descartes parte, como la conciencia, de la unidad como dato, o del ego como punto de partida (...) la situación nietzscheana de la filosofía es a de la carne misma: ser sorprendida por una prodigiosa diversidad, hacerse la pregunta de su unificación (preguntarse cómo asimilarla y comprenderla en la unidad), ésa es la situación fundamental de todo cuerpo vivo.' (2003, p. 133). Hacia aquí apunta a su vez Gemes al establecer que 'el ataque de Nietzsche hacia la metafísica esencialista dogmática es de hecho un llamado a abocarse a una autocreación propositiva bajo una voluntad unificante, una voluntad que posee la fuerza de reinterpretarse respecto del problema que somos.' (2001, p. 339). En este sentido, la 'gran salud' implicaría la maximización ascendente de dicha tendencia vital propia del Leib: la optimización de una unificación proyectivo-coordinativa. En el mismo sentido, y partiendo de esta multiplicidad a ser configurada, es que Olaffson asimismo sostiene que en Nietzsche puede entenderse "la imposición como expresión esencial de la vitalidad autoasertiva de cada ser viviente' (1991, p. 558). Vattimo, asimismo, plantea que la decadencia cultural se articula a una falta de ligazón orgánica con la vida, en tanto 'principio unificador' (2002: 40). Bacarlett Pérez sostiene que la capacidad autónoma del organismo, en Nietzsche, se alcanza 'a través de la pugna y la discordia entre las partes' propias de dicho ser vivo (2006, p. 68). Sin embargo, esto es caracterizar parcialmente a la posición nietzscheana; como marcamos, un cuerpo cuyas partes se hallan en permanente discordia resulta un cuerpo debilitado, no saludable, incapaz -justamente en tanto se halla absorbido por su permanente discordia- de hacer frente de modo eficaz a las fuerzas exteriores; la constante pugna ha de encontrar una modalidad saludable en la imposición de una determinada configuración, a través de la imposición de una perspectiva jerarquizante sobre las partes en pugna.

4 Naciente, puede decirse, en un doble sentido: por un lado, en tanto se busca poder dar marco a 
una psicopatología establecida a partir de un importante trabajo clínico -como da cuenta el segundo capítulo del Entwurf; por otro lado es naciente en tanto, en germen, se hallan allí muchas de las ideas que se desarrollan en sus posteriores trabajos teóricos. Para una ampliación de la relación conceptual entre el Entwurf y las posteriores obras freudianas, cfr. Bercherie (1996), Laplanche (1970), Boothby (2001), Kaufmann (1996), entre otros.

5 Este intento de síntesis no es, a fines del siglo XIX - el Proyecto data de 1895- un intento original -como Freud mismo lo señala, 'Hoy en día las tentativas de esta índole son frecuentes' ([1895] 1992, tomo I, p. 347).

6 En estos modelos se sustenta una dualidad opositiva neta, a partir de una instancia que se halla de forma determinada en conflicto con la sexualidad. Aquello que determina el segundo modelo pulsional no sustenta una oposición en términos de la naturaleza misma de las pulsiones en juego, sino a partir del objeto (Objekt) de las mismas. A partir de sus estudios sobre el narcisismo, Freud halla que el yo -sede de las pulsiones yoicas o autoconservativas- es capaz de hallarse impregnado de libido -energía sexual. Así, las pulsiones autoconservativas no pueden ya definirse en oposición a las sexuales; Freud opone entonces una libido del yo (Ichlibido) a una libido de objeto (Objektlibido). Al respecto, Green sostiene que 'la fase de oposición teórica entre libido de objeto y libido yoica amerita a mi ver la apelación de segunda teoría de las pulsiones (...). La convención se ha decidido a conservar la expresión de segunda y última teoría de las pulsiones para las ideas enunciadas en 1920 únicamente.' (2010, p. 18). Sulloway, por otro lado, sostiene que el último modelo pulsional implica 'la restauración de la división bipartita de la pulsión que había sido descolocada por la teoría del narcisimo.' (1992, p. 54).

7 La carta de Einstein se halla fechada en Caputh, cerca de Postdam, el 30 de julio de 1932.

8 Pero, ¿ese pensamiento autónomo no es asimilable a esa 'dictadura de la razón'? No, en tanto, en principio, ha de obrar en un contexto totalmente diverso: no sólo ha de soportar los embates pulsionales de otros, sino que ha de 'luchar por la verdad', es decir, ha de poder ejercer acción pulsional que implique tanto agresión -en tanto esa lucha implica imponerse en un medio hostil- como amor - por la verdad misma. Dicho de otro modo, requiere de elementos que exceden un puro pragmatismo.

9 Cfr. [1937] 1992, tomo XXIII, p. 200. No incluimos al superyó en esta descripción, pues no resulta relevante, en su especificidad, para articular en este punto la relación internoexterno -de hecho, Freud introduce al superyó, en su Resumen del psicoanálisis, en un apartado posterior al que trata la relación con el mundo exterior (Außenwelt) - es decir, no necesita del superyó para dar cuenta de dicha relación.

10 Así, Almeida sostiene que 'a la manera del artista, el niño se revela incansable en su juego de construcción y destrucción' (2005, p. 131).

11 'la gran salud- una salud que no sólo se posea, sino que además se conquiste y se tenga que conquistar continuamente, pues una y otra vez se la entrega, se la tiene que entregar...' (Nietzsche, [1888] 1979, p. 96).

12 'Una verdadera cultura ha de presuponer en toda circunstancia una unidad de estilo.' (Nietzsche, [1888] 2008, 9[152], p. 282).

13 Freud no establece una distinción determinada entre cultura y civilización (en su uso de ambos conceptos, los mismos apuntan a fungir como protección frente a la guerra) mientras que Nietzsche pone a la primera como propia de la vida ascendente: 'no confundir los medios disolventes de la civilización, que llevan necesariamente a la décadence, con la cultura.' ([1888] 2008, 15[67], p. 652).

14 'Así como el ello se agota con exclusividad en la ganancia de placer, el yo está gobernado por el miramiento a la seguridad. El yo se ha propuesto la tarea de la autoconservación, que el ello parece desdeñar.' ([1937] 1992, tomo XXIII, p. 201).

15 Por supuesto, aquí la referencia es al último modelo pulsional freudiano, que es el que interesa para el análisis aquí desplegado.

16 ¿Pero dicha indiferenciación no implica, por el contrario, la exacerbación del riesgo y por ende del conflicto? En términos de fuerzas, no: en tanto se trata de fuerzas activas y reactivas, dicha exacerbación implicaría la pura actividad -y por ende, el cese del conflicto activo/ reactivo; por otro lado, si a lo que se tiende es a la indiferenciación entre interior y 
exterior, desaparece asimismo el conflicto externo (ya no hay un viviente diferenciado que intenta incorporar exterior; en el extremo, interior y exterior coinciden).

17 Aquí entonces discrepamos con la apreciación de Assoun, quien afirma que si en Freud hay una base conflictiva dualista, en Nietzsche el conflicto "no es el motor fundamental de la dinámica pulsional', y la tendencia vital es la de un monismo dado por la voluntad de poder. (2008, p. 231). Por el contrario, el momento en que dicha voluntad de poder puede conformarse como guía determinante del viviente es a través de la configuración propia de la gran salud, caso que implica un determinado ordenamiento de la multiplicidad conflictiva de fuerzas; así, si según Nietzsche Spencer escamotea a las fuerzas activas, puede decirse que la interpretación de Assoun invierte dicho recorte, escamoteando, en este caso, las reactivas. De hecho, el caso analizado aquí donde habría una cancelación del conflicto remite a la indiferenciación del límite interno-externo, el cual no implica la formación óptima para lograr el plus de poder. Del mismo modo, en el caso freudiano también, según nuestro análisis, se produciría en la comunidad utópica una cancelación de la conflictividad bajo la dictadura de la razón - pero, nuevamente, se trata de casos específicos, y no de la concepción misma de vida en términos generales. Así, la invalidez reside en que Assoun estaría comparando el caso general en Freud, y uno específico en Nietzsche.

18 Por supuesto: si el conflicto interno provenía de la anarquía de fuerzas, y el externo en función de una incorporación de exterior, al no haber ya diferencia interno-externa necesariamente no hay conflicto.9 'El hombre es una cuerda tendida entre la bestia y el Superhombre. (...) Lo que debemos amar en el hombre es que consiste en un tránsito y un ocaso.' ([1885] 2007, p. 36). Tránsito, Übergang, proviene de Übergehen, traducible como 'pasar al otro lado', y también 'transitar'. Übergang, así, adquiere el sentido de 'pasar (a ser) otra cosa' -el Übermensch.

$20 \mathrm{Si}$ lo que hay en el caso freudiano es una completa unidad pragmática, la necesidad de normas de acción se desvanece - no hay ya nada que coartar y por ende, nada que obedecer salvo (de modo natural) a la propia razón. Vale notar: no hay necesidad siquiera de establecer un esquema constructivo a la manera del imperativo categórico kantiano (pues, a menos que se sea incapaz de razonamiento, la conducta a seguir resultaría a este tipo de comunidad evidente). 